\title{
Cauda equina syndrome caused by multiple intraspinal hemorrhage following percutaneous coronary intervention: a case report and a review of the literature
}

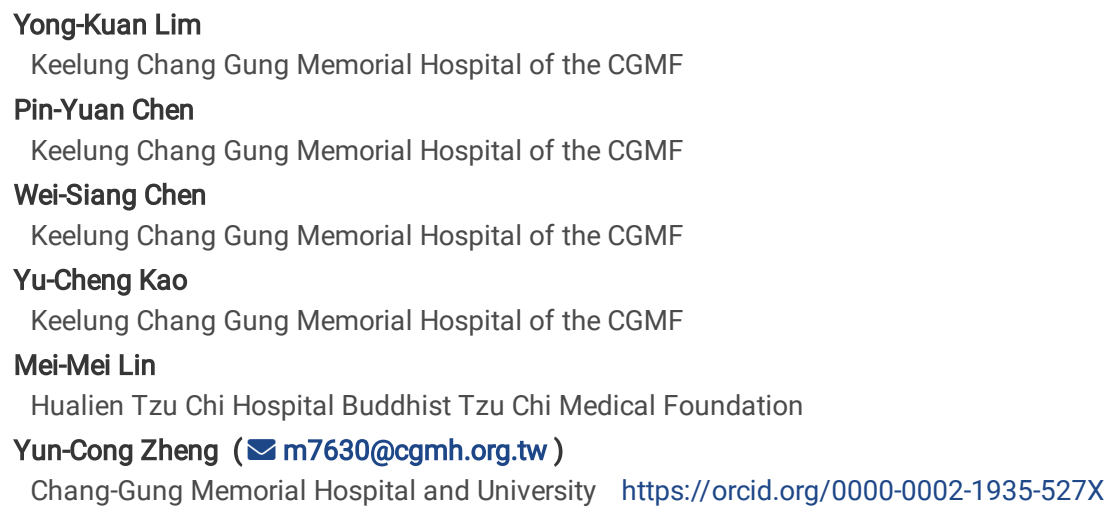

Keywords: Percutaneous coronary intervention, Cauda equina syndrome, Spontaneous spinal epidural hematoma, Spontaneous spinal subdural hematoma, Neurolysis

Posted Date: July 9th, 2021

DOI: https://doi.org/10.21203/rs.3.rs-691522/v1

License: @ (i) This work is licensed under a Creative Commons Attribution 4.0 International License. Read Full License 


\section{Abstract \\ Background}

Percutaneous coronary intervention and dual antiplatelet therapy are common management for patients with coronary artery disease. Multiple spontaneous intraspinal hematomas mixed with epidural hematoma and subdural hematoma following regular percutaneous coronary intervention is an extremely rare complication. We describe our experiences to treat the elderly who presented with spontaneous spinal epidural hematoma and subdural hematoma in different spinal locations after percutaneous coronary intervention. Neurological examination and magnetic resonance imaging were followed to assess the treatment outcomes for more than 2.5 years.

\section{Case presentation:}

In this article, we present a 70 years-old male taking dual antiplatelet therapy for 1 year after drug-eluting stents implantation to right coronary artery and left anterior descending artery for non-ST elevation myocardial infarction had a sudden onset of paraplegia then the autonomic dysfunction immediately after another percutaneous coronary intervention. Whole spinal MRI showed mixed spontaneous spinal subdural hematoma and spinal subdural hematoma, included: anterior C5-T3 acute subdural hemorrhage, right lateral T4 to T8 epidural hemorrhage, and L5-S1 intrathecal hematoma. After urgent cauda equina neurolysis and T7-9 laminectomy to evacuate spinal epidural hemorrhage in accordance with the neurological symptoms, the patient regained walking ability immediately. The urination and defecation function recovered then. The surgical results maintained for at less 2.5 years, even after another percutaneous coronary intervention 1 year later.

\section{Conclusions}

Intraspinal hematomas in acute coronary syndromes are scarce but critical conditions after percutaneous coronary intervention. Multiple mixed spontaneous spinal subdural hematoma/ epidural hematoma could be fully reversed by circumspect neurolysis and limited laminectomy timely.

\section{Background}

A spontaneous spinal epidural hematoma (SSEH), defined by bleeding in the epidural space of the spine related to atraumatic etiology, with an incidence about 0.1 per 100,000 patients per year [1]. It is rare but a catastrophic neurological condition, usually need urgent surgical decompression [2, 3]. A spontaneous spinal subdural hematoma (SSDH), associated with permanent neurological deficits, is much less common than SSEH [4-6]. The clinical symptoms of SSEH or SSDH are sudden onset of neck or back pain initially associated with motor and/or sensory deficits in limbs, indicating spinal cord compression caused by the hematoma [7, 8]. Multiple intraspinal hematomas are more serious clinical conditions. As far as I know, mixed SSEH and SSDH causing CES as a complication of PCl has not been well documented.

Bleeding in the management of acute coronary syndromes (ACS) and percutaneous coronary intervention (PCI) has emerged in recent years, although it is relatively less to ischemic complications [9]. Mixed SSEH and SSDH following PCl lead to CES is true urgency to operation, especially in patients with rapid neurological deterioration. Meanwhile, platelet activation blocked by DAPT raises the difficulties of neurosurgery. We shared our management strategies for the CES caused by SSEH and SSDH. This scarce case highlights the importance of smooth coordination between cardiologist and neurosurgeon after the PCI to cope with possible complications of intraspinal hematomas.

\section{Case Presentation}

A 70-years-old male had no major medical history before until 4 years ago when he diagnosed as non-ST elevation myocardial infarction (NSTEMI), Killip 1. $\mathrm{PCl}$ was emergently introduced to the patient and coronary angiogram revealed coronary artery disease (CAD) with 2-vessel-occlusion. Successful percutaneous coronary angioplasty (PCA) from both radial arteries with 6F catheters and then drug-eluting stent (DES) for right coronary artery and left anterior descending artery were done. The patient had uneventful recovery following the procedure and he was discharged under DAPT control (aspirin at a dose of $100 \mathrm{mg}$ once daily and ticagrelor at a dose of $90 \mathrm{mg}$ twice daily). After 1 year of DAPT treatment, the medication was shifted to monotherapy with aspirin at a dose of $100 \mathrm{mg}$ once daily for 3 years.

\section{Percutaneous coronary intervention}

This time, he presented to a medical clinic with sudden onset retrosternal pain with radiation to back. After the transfer into our emergent room under the suspicion of ACS attack, the electrocardiogram disclosed equivocal ST-elevation with T-wave inversion. Ejection fraction of left ventricular was $61 \%$ in $2 \mathrm{D}$ echocardiogram and Troponin-T was as high as $329.4 \mathrm{mg} / \mathrm{dl}$. NSTEMI was impressed, $40 \mathrm{mg}$ methylprednisolone and local anesthesia with $2 \%$ lidocaine were prescribed as premedication. Cardiac catheterization revealed total occlusion of left circumflex artery majorly. PCl with $6 \mathrm{~F}$ sheath was introduced from right radial artery and DES of Medtronic Resolute $2.5 * 38 \mathrm{~mm}$ was placed to left circumflex artery. Activated clotting times of 290 to 300 seonds were maintained by using a weight-based dosing of 60 to $70 \mathrm{U} / \mathrm{kg}$ of heparin. DAPT (a aspirin at a dose of $100 \mathrm{mg}$ once daily and ticagrelor at a dose of $90 \mathrm{mg}$ twice daily) continued after the procedure.

\section{Cauda equina syndrome}


On admission to intensive care unit, vital signs were within normal ranges. Three hours after the PCl, he complained of severe backache from mid-thoracic to lower cervical level and it failed to relieve after acetaminophen $500 \mathrm{mg}$ oral intake. The patient stated no traumatic history since the last stent implantation 4 years ago. Then right leg weakness developed: Medical Research Council (MRC) scale down from 5/5 to 2/5, and it progressed to left lower extremity gradually. The strength of upper extremities remained intact. Bilateral pupil size was $3.0+/ 3.0+$ and there was no sensation while urinating and defecating. Brain computed tomography for possible ischemic complication found no corresponding lesions. Neurological examination executed by the consulted neurologist disclosed acute paraplegia within 1 hour (MRC scale of bilateral lower extremities: 1/5) with hypoesthesia below T7 level, nearly anesthesia on lower limbs, and positive Babinski signs. Saddle anesthesia complicated with urine retention and incontinence led to indwelling catheter dependent. Rectal examination showed flaccid anal sphincter and reflex of bilateral Achilles' tendon decreased.

The patient had no chest pain, dyspnea exacerbation, loss of consciousness, dizziness, upper limbs weakness, facial palsy, disorientation, and blurred speech. The neurologist suggested CES rather than ischemic stroke. The auxiliary data of the blood and coagulation parameters showed mildly decreased platelet count (145/L) and high Troponin-T (2336 mg/dl) but other coagulation factors were within the normal range (Table 1). Magnetic resonance imaging (MRI) of the spine revealed multiple intraspinal hematomas, include: C5 to T3 segmental subdural hematoma ventral to the spinal cord (Fig. $1 \mathrm{AB}$ ), T4 to T8 epidural hematoma compressed the spinal cord dorsally (Fig. 1CD), and intrathecal hematoma at L5 to S1 deviated the nerve roots from normal distribution (Fig. 1EF). Interrupted intraspinal hematomas distorted the cord and cauda equina.

\section{Surgical strategies}

Dexamethasone phosphate $5 \mathrm{mg}$ was given via intravenous route to reduce secondary neurological insults and acetaminophen was held due to critical bleeding with increasing Troponin-T. The neurosurgery team discussed the urgent situation about CES and possible treatment options with his daughter. After the hesitation of other family members, surgical decompression carried out immediately within 8 hours after neurological symptoms attacks. L5 to upper S2 wide laminectomy was performed initially for the incontinence (Fig. 2A). A $4.5 \mathrm{~cm}$ cyst content with blood compressed underlying eliminated (Fig. $2 \mathrm{AB}$ ) and further neurolysis to roots of the cauda equina executed cautiously under the microscope (Fig. $2 \mathrm{C}$ ). No anatomical variations were detected during surgery. Dural closure was accomplished after good hemostasis (Fig. 2D).

Due to incomplete spinal cord impairment below T7 level, we decided to perform limited T7 to T9 laminectomy to evacuate the epidural hematoma. Liquefied hematoma gashed out with pressure and was aspirated to achieve full cord decompression. Two epidural drains guaranteed the relief of epidural pressure then. Total operation time was 6 hours and blood loss was $400 \mathrm{cc}$. $12 \mathrm{U}$ platelet transfusion was done following the operation. We took conservative observation to cervical subdural hematoma because no obvious neurological signs over upper limbs and no severe cord compromised by hematoma.

\section{Multidisciplinary care}

After the surgery, we withdrew ticagrelor and adjusted the DAPT as aspirin at a dose of $100 \mathrm{mg}$ once daily and clopidogrel at a dose of $90 \mathrm{mg}$ once daily. Intravenous dexamethasone phosphate $10 \mathrm{mg}$ continued four times daily. Immediately, muscle strength of left lower leg near totally recovered on postoperative day 1 (MRC scale of left lower extremity: 4/5). The neurological deficits kept improving include saddle sensation and he was transferred to neurosurgery ward under lumbar brace protection on postoperative day 2 as gradually declined Troponin-T level. On postoperative day 5, epidural drains were pulled out. Muscle strength of lower extremities continued improving after the hemovac drains removal on postoperative days 5 through 9 . The movement became symmetry (MRC scale of bilateral lower extremities: 4+/5) on postoperative day 10 under comprehensive rehabilitation. And he started to aware urination and stool passage but still was unable to control it. He tried the catheter removal but failed due to hematuria and the difficulty in voiding after that. On postoperative day 15 , he could sit at a wheelchair stably without numbness over the saddle area. On postoperative day 17 , the patient was able to ambulation without assistance. He was discharged home without fecal incontinence on day 30 . The outpatient urology follow-up was arranged since Foley catheter dependence.

\section{Postoperative follow-up}

DAPT therapy backed to aspirin and ticagrelor after the hematuria improved. Benign prostatic hyperplasia was diagnosed at the urology clinics. After medication, self urination achieved one month later (Fig. 3). Two months after the surgery, spinal MRI revealed the resolution of hematomas and the regression of the mass effect over the whole spinal cord but residual seroma over the lumbosacral junction left (Fig. 1G). The patient returned to his normal life independently without obvious neurological sequelae.

Half-year later, he received scheduled PCI for the restenosis of previous DES noted by the last coronary angiogram. DES for left main to the proximal anterior descending artery and distal right coronary artery were installed smoothly under proper sedation and analgesics control. There were no bleeding complications of the PCI. The same DAPT continued to prevent stent thrombosis and the benefits of neurosurgical intervention maintained without recurrence till now (Fig. 4). The seroma was replaced by contrast-enhancing granulation at $L 5$ level in MRI follow-up 18 months after the operation leading to mild numbness over right calf laterally which didn't influence the quality of daily life (Fig. $1 \mathrm{H}$ ).

\section{Discussion}

Our report of the first documented case of CES caused by segmental SSEH and SSDH as a complication of PCI with DES illustrates several aspects of this emergency event that are still not fully understood. The patient had received aspirin and ticagrelor as DAPT before and after this PCl in recent 5 years. According to the time frame, he suffered from CES immediately after the PCI. It was thought to be the major cause of spontaneous spinal hematomas, rather than DAPT. 
From a study reported by Philippe Gabriel Steg, the frequency of bleeding in ACS and PCl underestimated due to the highly selected patients at low risk of bleeding. And the increasing use of combinations of antithrombotic drugs and PCl may increase the risk of bleeding complications. The bleeding rate was higher in the primary PCl than elective PCl and the bleeding site was more common on the arterial access site [9]. Our case had multiple intraspinal bleeding sites was extremely rare.

Older age, lower body weight, and invasive procedures use were powerful predictors of bleeding complications in ACS and PCI. In a study by Moscucc, the adjusted odds of having a major hemorrhage prior to discharge increase by about 30\% per decade of age as reported in Global Registry of Acute Coronary Events (GRACE) [10]. The hypothesis is that collagen and amyloid deposits in the tunica media layer of the vascular, increase with aging, may cause brittle vessels that are less inclined to constrict and are more prone to bleed [10].

Until now, the cause of the SSEH is still controversial and it doesn't have a definitive known cause for most of the cases, as well as SSDH, due to its rarity in general populations (Table 2). Some believed that SSEH is caused by the ruptured epidural veins of the weakened venous plexus especially at the dorsal epidural veins of the spinal cord [3]. Meanwhile, SSDH tends to occur on the ventral side of the spinal canal since the dura matter adheres more tightly to the posterior longitudinal ligament than the ligamentum flavum $[11,12]$. They hypothesized "a minor trauma or forgotten effort leading to increased intrathoracic and intraluminal pressure of the vessels traversing the subarachnoid space" is the etiology of SSDH [13, 14].

The Valsalva maneuver may increase intra-abdominal and intra-thoracic pressure which transferred to the spinal epidural venous system and makes the valveless nature of the epidural venous plexus ruptured [15]. The consequently elevated intra-thoracic pressure could also damage intraluminal vessels. This vicious circle probably leads to mixed SSEH and SSDH present at the same time. Although we cannot verify the direct etiologies, we suggest that the preexisting weakened venous wall due to aging, the DAPT therapy for ACS and the Valsalva maneuver due to discomfort during the period of the PCI intervention contributed to the segmental SSED with SSDH and following CES.

When bleeding complications occur, the area of hematoma is hard to self-limited due to concurrent DAPT that inhibits the activity of the platelet. We adjusted the DAPT as aspirin and clopidogrel according to more pronounced platelet inhibition effect and higher rate of non-procedure-related bleeding along with ticagrelor [16]. After the neurosurgery, we shifted the DAPT back to aspirin and ticagrelor to prevent thromboembolic events of the PCl intervention based on the guideline for the management of patients with NSTE-ACS $[17,18]$.

\section{Conclusion}

As more aggressive intervention and anti-thrombotic therapy established for ACS, complications of the spinal hematomas should be taken into consideration. The outcome of SSEH and SSDH could be favorable if it is diagnosed timely and treated early. If the duration of the complete neurological deficits is less than 12 hours, it still could be reversed by the urgent operation [7].

\section{Abbreviations}

\section{ACS}

acute coronary syndromes

CAD

coronary artery disease

DAPT

dual antiplatelet agents

DES

drug-eluting stent

MRC

Medical Research Council

MRI

magnetic resonance imaging

\section{NSTE-ACS}

non-ST elevation acute coronary syndrome

NSTEMI

non-ST elevation myocardial infarction

PCA

percutaneous coronary angioplasty

$\mathrm{PCl}$

percutaneous coronary intervention

SSDH

spontaneous spinal subdural hematoma

SSEH

spontaneous spinal epidural hematoma

\section{Declarations}


Ethical approval: All procedures performed in studies involving human participants were in accordance with the ethical standards of the institutional and with the 1964 Helsinki declaration and its later

Consent to participate: The need for consent to participate was waived by above committee. The IRB is organized and operates in accordance with Good Clinical Practice and the applicable laws and regulations (IRB file No 202000270B0). Thus, our study was followed by the World Journal of Emergency Surgery guidelines of retrospective ethics approval.

Availability of data and material: The datasets generated during and/or analysed during the current study are available from the corresponding author on reasonable request

Competing interests: All authors certify that they have no affiliations with or involvement in any organization or entity with any financial interest (such as honoraria; educational grants; participation in speakers' bureaus; membership, employment, consultancies, stock ownership, or other equity interest; and expert testimony or patent-licensing arrangements), or non-financial interest (such as personal or professional relationships, affiliations, knowledge or beliefs) in the subject matter or materials discussed in this manuscript.

Funding: No funding was received for this research

\section{Authors' contributions:}

Zheng YC, Lim YK, Chen PY, Chen WS, Kao YC, Lin MM contributed to the data collection and analysis.

Zheng YC, Lim YK, Chen PY contributed to the conception and design of the study

Zheng YC and Lim YK contributed to drafting the text and preparing the figures

\section{Acknowledgments:}

The authors would like to thank the clinicians, the patient, and all investigators contributed to this study. We also thank Cancer Center of Chang Gung Memorial Hospital, Keelung and Linkou branches, for their excellent support.

Disclosures: The authors report no conflict of interest concerning the materials or methods used in this study or the findings specified in this paper.

Dr. Yun-Cong Zheng, as a corresponding author as mentioned above had nothing to disclose of the submitted work which title "Treat cauda equina syndrome following percutaneous coronary intervention" (Including grants, data monitoring board, study design, manuscript preparation, statistical analysis, etc.)

\section{Formatting of funding sources:}

This research did not receive any specific grant from funding agencies in the public, commercial, or not-for-profit sectors.

\section{References}

1. Holtas S, Heiling M, Lonntoft M. Spontaneous spinal epidural hematoma: findings at MR imaging and clinical correlation. Radiology. 1996;199(2):40913.

2. McHaourab A, Evans GYR, Austin R. Spontaneous spinal subdural haematoma in a patient on apixaban. BMJ Case Rep. 2019;12(1).

3. Yamaguchi K, Mathew J, Lhi JM, Park DY. Acute and Rapid Development of Spontaneous Spinal Epidural Hematoma Associated with Combined AspirinDipyridamole Therapy: A Case Report. JBJS Case Connect. 2017;7(1):e19.

4. Pereira BJ, de Almeida AN, Muio VM, de Oliveira JG, de Holanda CV, Fonseca NC. Predictors of Outcome in Nontraumatic Spontaneous Acute Spinal Subdural Hematoma: Case Report and Literature Review. World Neurosurg. 2016;89:574-7 e7.

5. Pullarkat VA, Kalapura T, Pincus M, Baskharoun R. Intraspinal hemorrhage complicating oral anticoagulant therapy: an unusual case of cervical hematomyelia and a review of the literature. Arch Intern Med. 2000;160(2):237-40.

6. Gan CW, Chen SY, Chang CS, Liu JD. Spontaneous Spinal Subdural Hematoma: Case Report of 2 Years' Clinical and Radiologic Findings. World Neurosurg. 2019;127:275-8

7. Liao CC, Lee ST, Hsu WC, Chen LR, Lui TN, Lee SC. Experience in the surgical management of spontaneous spinal epidural hematoma. J Neurosurg. 2004;100(1 Suppl Spine):38-45.

8. Li X, Yang G, Wen Z, Lou X, Lin X. Surgical treatment of progressive cauda equina compression caused by spontaneous spinal subdural hematoma: A case report. Medicine. 2019;98(12):e14598.

9. Steg PG, Huber K, Andreotti F, Arnesen H, Atar D, Badimon L, et al. Bleeding in acute coronary syndromes and percutaneous coronary interventions: position paper by the Working Group on Thrombosis of the European Society of Cardiology. Eur Heart J. 2011;32(15):1854-64.

10. Moscucci M, Fox KA, Cannon CP, Klein W, Lopez-Sendon J, Montalescot G, et al. Predictors of major bleeding in acute coronary syndromes: the Global Registry of Acute Coronary Events (GRACE). Eur Heart J. 2003;24(20):1815-23. 
11. Domenicucci M, Ramieri A, Ciappetta P, Delfini R. Nontraumatic acute spinal subdural hematoma: report of five cases and review of the literature. J Neurosurg. 1999;91(1 Suppl):65-73.

12. Pierce JL, Donahue JH, Nacey NC, Quirk CR, Perry MT, Faulconer N, et al. Spinal Hematomas: What a Radiologist Needs to Know. Radiographics. 2018;38(5):1516-35.

13. Rader JP. Chronic subdural hematoma of the spinal cord: report of a case. N Engl J Med. 1955;253(9):374-6.

14. Kakitsubata Y, Theodorou SJ, Theodorou DJ, Miyata Y, Ito Y, Yuki Y, et al. Spontaneous spinal subarachnoid hemorrhage associated with subdural hematoma at different spinal levels. Emerg Radiol. 2010;17(1):69-72.

15. Seon HJ, Song MK, Han JY, Choi IS, Lee SG. Spontaneous cervical epidural hematoma presenting as brown-sequard syndrome following repetitive korean traditional deep bows. Ann Rehabil Med. 2013;37(1):123-6.

16. Wallentin L, Becker RC, Budaj A, Cannon CP, Emanuelsson H, Held C, et al. Ticagrelor versus clopidogrel in patients with acute coronary syndromes. N Engl J Med. 2009;361(11):1045-57.

17. Amsterdam EA, Wenger NK, Brindis RG, Casey DE Jr, Ganiats TG, Holmes DR Jr, et al. 2014 AHA/ACC Guideline for the Management of Patients with NonST-Elevation Acute Coronary Syndromes: a report of the American College of Cardiology/American Heart Association Task Force on Practice Guidelines. J Am Coll Cardiol. 2014;64(24):e139-228.

18. Braunwald E. Braunwald's heart disease: a textbook of cardiovascular medicine. In: 11, editor. 60. Philadelphia: Elsevier/Saunders; 2019. pp. $1181-208$.

\section{Tables}

Table 1 Laboratory data of patient at symptoms presentation

\begin{tabular}{|lll|}
\hline Variable & Reference ranget, adults & On presentation \\
\hline Hematocrit (\%) & $41-53$ & 35.3 \\
\hline Hemoglobin (g/dl) & $13.5-17.5$ & 13.0 \\
\hline White cell count (per mm3) & $4500-11,000$ & 8700 \\
\hline Differential count (\%) & & \\
\hline Neutrophils & $40-70$ & 80.3 \\
\hline Lymphocytes & $22-44$ & 14.2 \\
\hline Monocytes & $4-11$ & 4.7 \\
\hline Eosinophils & $0-8$ & 0.6 \\
\hline Basophils & $0-3$ & 0.2 \\
\hline Platelet count (per mm3) & $150,000-400,000$ & 145,000 \\
\hline Red cell count (per mm3) & $4,500,000-5,900,000$ & $3,970,000$ \\
\hline Mean corpuscular volume (fl) & $80-100$ & 88.9 \\
\hline Mean corpuscular hemoglobin (pg) & $26-34$ & 32.7 \\
\hline Mean corpuscular hemoglobin level (g/dl) & $31-37$ & 36.8 \\
\hline Red cell distribution width (\%) & $11.5-14.5$ & 12.3 \\
\hline Prothrombin time (sec) & $11-14$ & 11.4 \\
\hline Prothrombin time international normalized ratio & $0.9-1.1$ & 31.1 \\
\hline Partial thromboplastin time, activated (sec) & $22.1-35.1$ & \\
\hline
\end{tabular}

tReference values are affected by many variables, including the patient population and the laboratory methods used. The ranges used at Chang Gung Memorial Hospital are for adults who are not pregnant and do not have medical conditions that could affect the results. They may therefore not be appropriate for all patients.

Table 2 Overview of articles involved in spontaneous intraspinal haemorrhages 


\section{Spontaneous spinal hemorrhage types and possible causes}

SSEH

(Causes: minor trauma and anticoagulant therapy)

SSDH

(Outcome: prognosis is determined by the the neurological status at presentation)

\section{References}

Holtas S, Heiling M, Lonntoft M. S epidural hematoma: findings at MI clinical correlation. Radiology 1991

13.

Pereira BJ de Almeida AN Muio VM, de Oliveira JG, de Holanda CV, Predictors of Outcome in Nontraur Acute Spinal Subdural Hematoma and Literature Review. World Neurc

2016;89:574-7 e7.

Pullarkat VA, Kalapura T, Pincus M Intraspinal

hemorrhage complicating oral anti unusual case of cervical hematom of the

literature. Arch Intern Med 2000;16

\section{SSEH}

(Treatment: Surgery approach)

Liao CC, Lee ST, Hsu WC, Chen LR, Experience in the surgical manage spontaneous spinal epidural hema Neurosurg 2004;100(1 Suppl Spint

\section{SSDH}

(Treatment: Laminectomy and subdural evacuation tx)

Li X, Yang G, Wen Z, Lou X, Lin X. ऽ progressive cauda equina compres by spontaneous spinal subdural $h$ report. Medicine (Baltimore)

2019;98(12):e14598.

\section{SSEH}

(Causes: low dose aspirin)

Phang ZH, Chew JJ, A/P Thurairaj $\mathrm{SaB}$. Spontaneous Spinal Epidural With the Use of Low-dose Aspirin i Acad Orthop Surg Glob Res Rev $2 C$

\section{SSDH}

(Treatment: conservative/surgery)

Gan CW, Chen SY, Chang CS, Liu J Subdural Hematoma: Case Report Years' Clinical and Radiologic Find

Neurosurg 2019;127:275-8.

SSEH

(Causes: aspirin-dipyridamole)

Yamaguchi K, Mathew J, Lhi JM, F Rapid Development

of Spontaneous Spinal Epidural $\mathrm{H}_{\mathrm{i}}$ with Combined Aspirin- Dipyridam A Case Report.

JBJS Case Connect 2017;7(1):e19

SSDH

(Treatment: conservative/surgery)

Domenicucci M, Ramieri A, Ciappe Nontraumatic acute spinal subdur five cases and review of the literatı

1999;91(1 Suppl):65-73.

Combined Spinal SAH and SDH (Causes: intrathoracic and intraluminal pressure + physical pressure)

Kakitsubata $Y$, Theodorou

SJ, Theodorou DJ, Miyata Y, Ito $Y_{\text {, }}$ Spontaneous spinal subarachnoid associated with subdural hemator levels.

Emerg Radiol 2010;17(1):69-72.

SSEH

(Causes: increased venous pressure)

Seon $\mathrm{H}-\mathrm{J}$, Song M-K, Han J-Y, Choi Spontaneous cervical epidural hen brown- sequard syndrome followir

korean traditional deep bows. Ann 2013;37(1):123-6

Spontaneous bleeding not related to $\mathrm{PCl}$, including fatal intracranial bleeding and fewer of fatal bleeding of other types

(Causes: Ticaglelor)
Wallentin L, Becker RC, Budaj A, Cé $H$, Held $C$, et al. Ticagrelor versus $C$ in patients with acute coronary syr

N Engl J Med 2009;361(11):1045-!

\section{Figures}



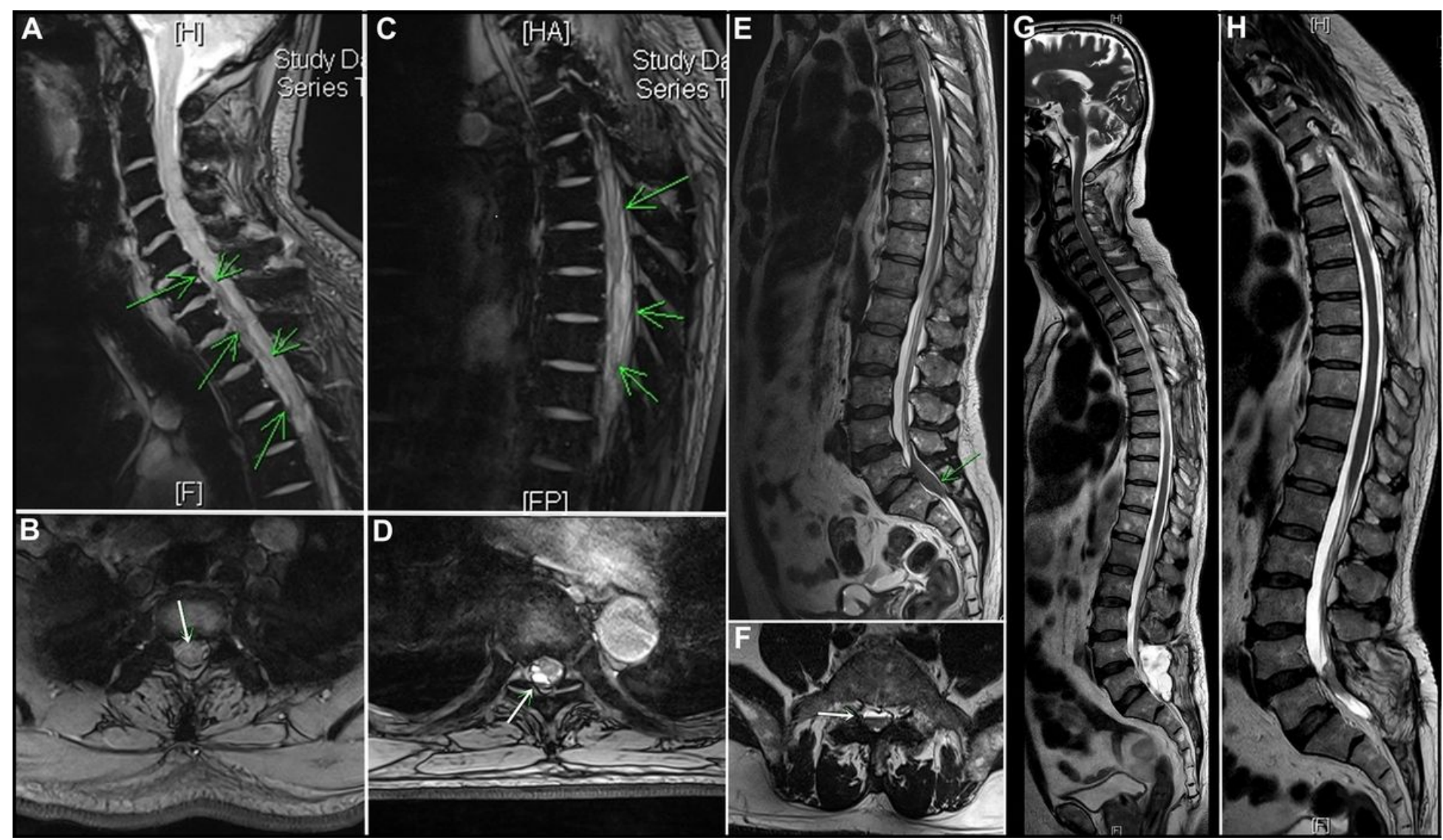

Figure 1

Serial T2-weighted magnetic resonance rmages before and after the event. Whole spinal MRI at symptoms onset revealed C5 to T3 segmental subdural hematoma ventral to the spinal cord and presented slight hyperintensity in the sagittal view (A) and the axial view (B). Another high signal epidural hemorrhage extended from T4 to T8 right laterally, causing compressive myelopathy in the sagittal view (C) and the axial view (D). Moreover, the deposit of intrathecal hematoma at the L5-S1 level showed hypointensity in the sagittal view (E) and the axial view (F). The Sagittal MRI that was performed 2 months after the operation showed the complete resolution of cervicothoracic hemorrhage with a $6.8 \mathrm{~cm}$ residual seroma at L4-S1 level (G). At one and a half years following the event, the spinal hemorrhage was completely resolved, and L5 granulation tissue remained $(\mathrm{H})$. Green arrows in the sagittal view marked the area of intraspinal hematomas. White arrows in the axial view indicated the boundary between hematomas and spinal cord or roots. 


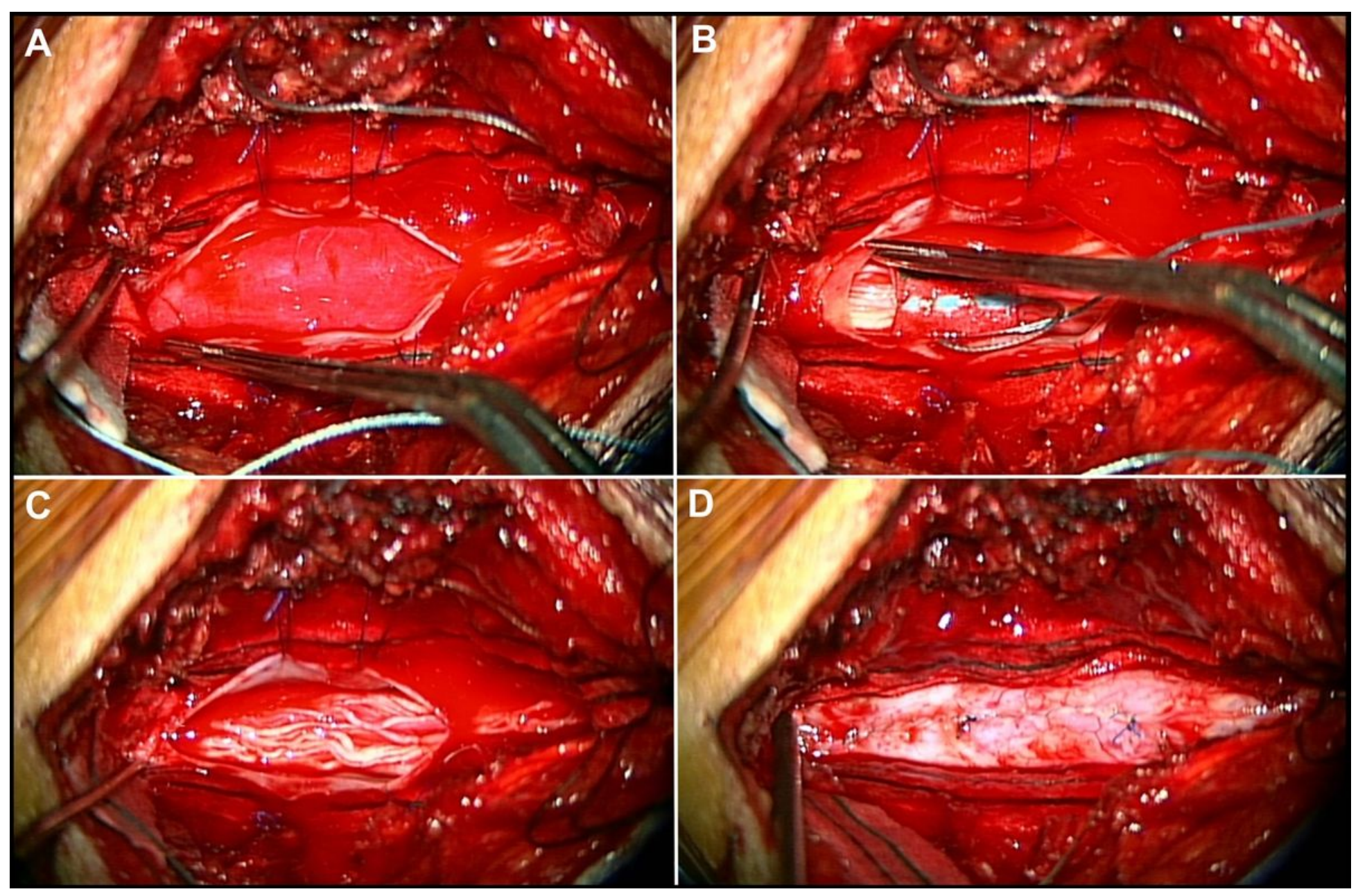

Figure 2

Surgical procedure and intra-operative findings in lumbosacral spine. (A) shows a $4.5 \mathrm{~cm}$ cystic lesion with blood content causing tension in cauda equine after L5 to the upper S2 laminectomy and dura mater opening. (B) shows the ventral displacement of cauda equina during the removal of the mass. (C) shows nerve root preservation under the microsurgical neurolysis of cauda equine, thereby further relieving the tension. (D) shows dural closure after good hemostasis. 


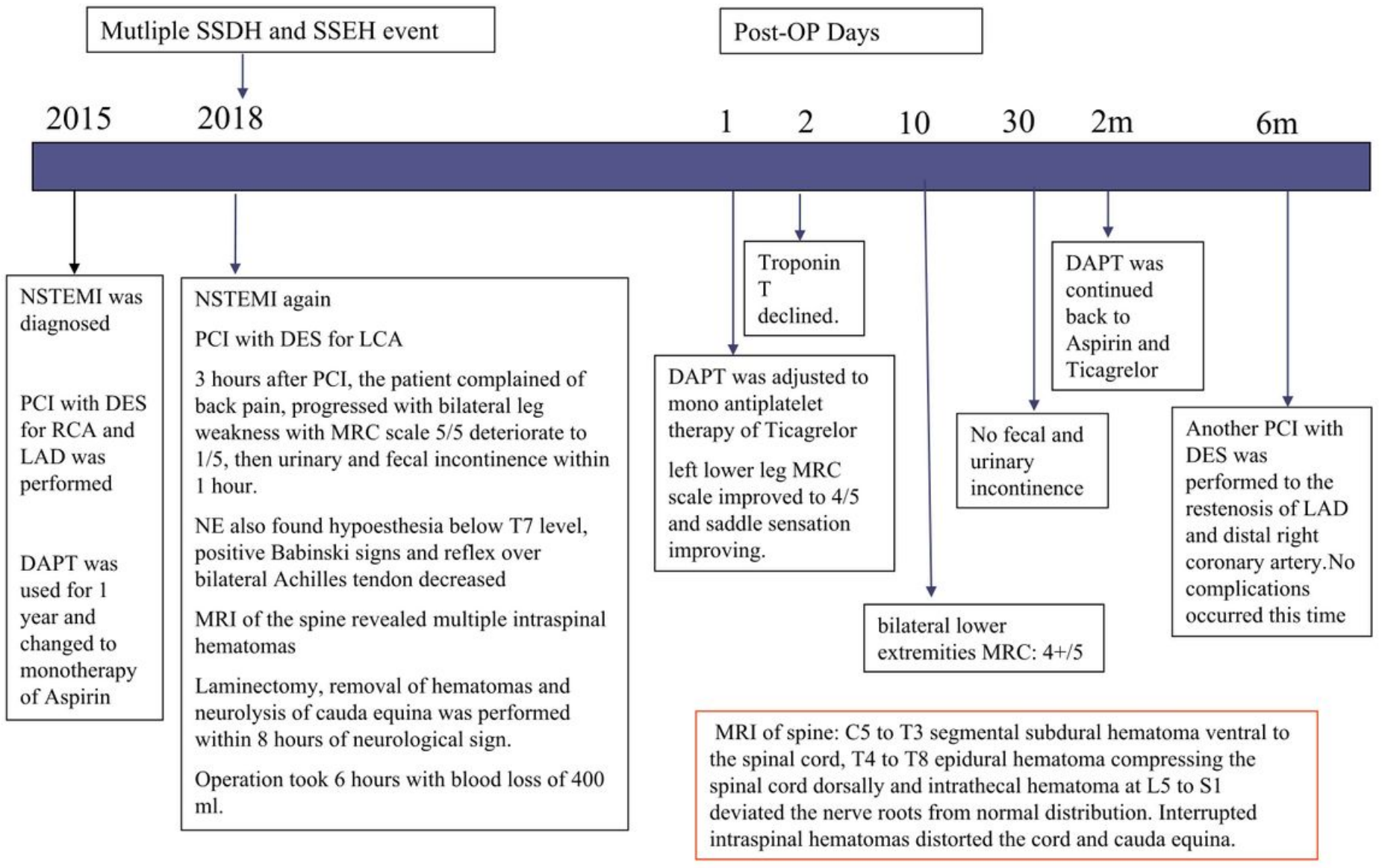

Figure 3

Summary of the emergent course

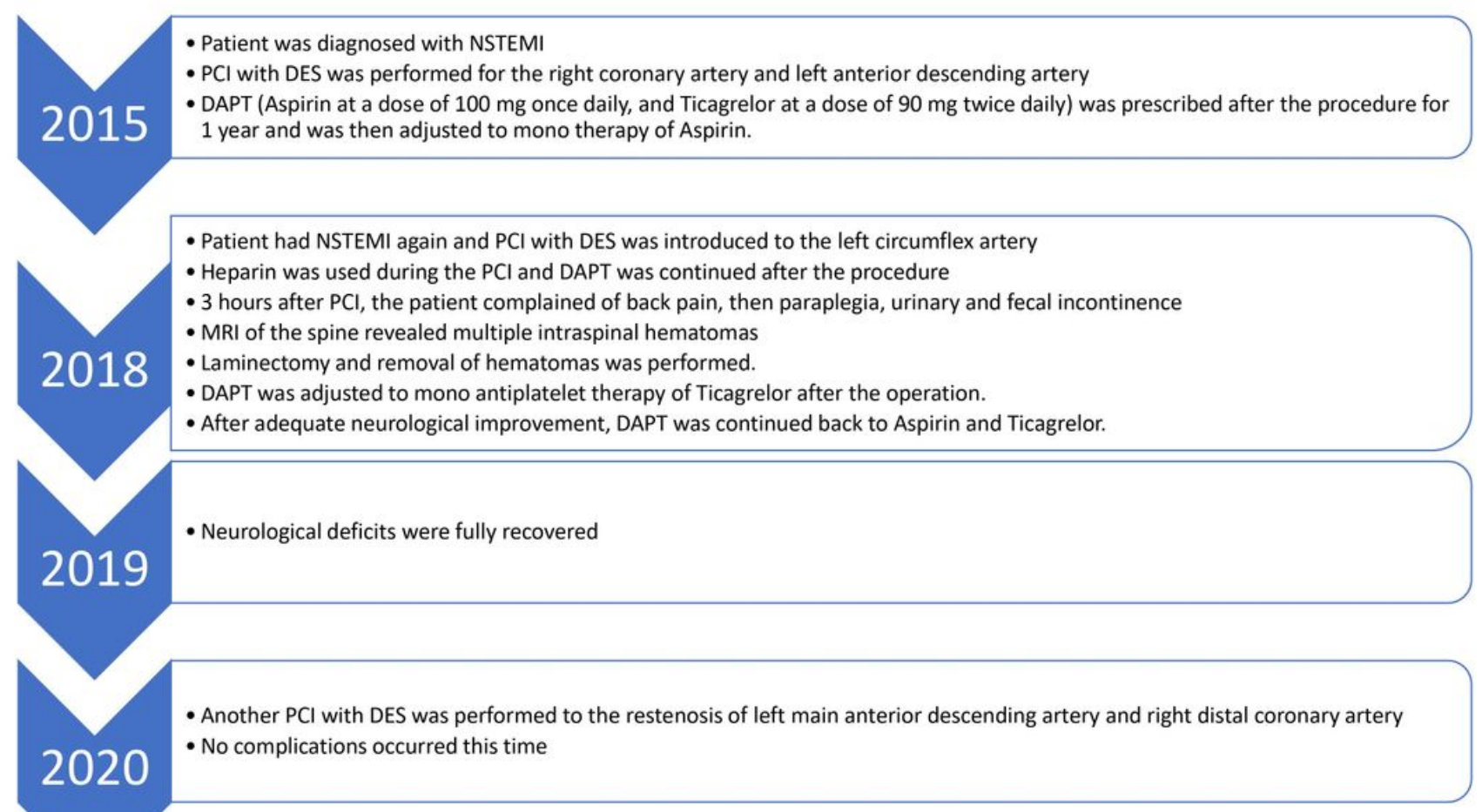


Figure 4

Summary of the longterm outcomes

Page $11 / 11$ 